\title{
The Business English Teaching Reform Under The Perspective OF The CBI Teaching Concept
}

\author{
Jun Zhao ${ }^{1}$ \\ ${ }^{1}$ Neijiang Normal University, Neijiang, Sichuan Province, China
}

Keywords: Content-Based Instruction, English teaching, teaching model, Business English

\begin{abstract}
Relying on teaching content (Content-Based Instruction, referred to as "CBI") to emphasize that the subject matter and language learning combine to improve students' academic knowledge and cognitive skills, while promoting the development of their language skills. At home, on the theory and empirical research CBI has a lot in practice has made teaching experience. With the rapid development of China's foreign trade, business English has become a very popular profession. This article will rely on the content of the application of the teaching of English in business, and look forward to a combination of both, a good way to explore business English teaching.
\end{abstract}

\section{Introduction}

Business English is a living language requirement to adapt the workplace for the purpose of covering all aspects of the business activities. Business English courses are not simply on the level of students' English ability improved, it is to teach students more a Western concept of enterprise management, work psychology, and even how to deal with foreigners, and how they collaborate, work ways, and their living habits, to some extent is included in the concept of culture [1].

Business English itself has "interdisciplinary" feature, which to cultivate their English skills and business knowledge combined with complex talent as the goal. Therefore, business English teaching should not only pay attention to the language and skills, but also pay attention to the business professional content, two elements are indispensable. How will foreign language teaching and teaching organic integration is the key to the success of business English teaching.

\section{Meaning content teaching philosophy}

Relying on foreign language teaching course content is the rise in the 1980s of a second language or foreign language teaching approach. This will be the target language and subject matter fully integrated with teaching philosophy is to optimize a second or foreign language learning provides a new perspective. The classroom, the direct object of language is not only learning but also as a means of learning a particular topic [1]. Therefore, teachers in teaching should not deliberately teach grammar, language function, or locales, such as knowledge of the language, but should focus on teaching content. By teaching content, while students in the language as a tool to acquire knowledge naturally enhance the ability to use this language.

CBI researchers believe that this teaching approach should not be a fixed teaching methods. Rather, it is a flexible framework for the operation of teaching, there is a wide choice of teaching mode and method of use to meet the needs of different scenarios and teaching purposes [1]. Stryker \& Leaver and so that CBI truly holistic teaching foreign language, it can be a research-oriented, but can also be a methodology, a concrete frame structure of the entire curriculum design or teaching projects.

CBI teaching philosophy Interpretation. CBI, the English name "Content- based Instruction", also known as content-based teaching is a content-based, relying on teaching methods (Han Bing et al, 2005). CBI teaching philosophy is to have to learn the target language (English), as a carrier, through the study of theoretical knowledge of other disciplines in the classroom, to master the English language, this teaching philosophy, the target language and other subjects in the content of organic integration Together, compared with the traditional English teaching, is a new type of foreign language teaching. Its novelty lies in learning the target language does not directly, but to shift the focus from teaching to learning the language itself by learning other subjects' knowledge to learn and 
master the target language [2]. CBI teaching has been produced since 1980 gradually matured, now has as a typical example of language teaching, which at the same time, students of various disciplines of knowledge concept, subtly enhance the students' English proficiency. CBI teaching philosophy and teaching targeted marketing professional English teaching coincide, first, we must improve students 'language skills; second, we must enhance students' knowledge of other disciplines literacy. So, with the combination of marketing CBI teaching English teaching theory, called the perfect fit. In the classroom, students use English (instead of native Chinese) this medium to learn these different disciplines and theoretical knowledge in these courses, while students not only mastered the subjects theoretical knowledge, and ultimately achieve the purpose of learning the target language, kill two birds with great meaning.

CBI teaching theoretical model. CBI teaching philosophy is a content-based foreign language teaching methods by learning other subjects and theoretical knowledge to learn the target language, CBI teaching philosophy teaching model first asked subjects to learn core content knowledge and theory; secondly requirements apply language materials should be derived from the authentic language materials; third, requiring teachers to teach the students to learn the information should be the new information; fourth, a different student learning when teachers should have a different curriculum. These are the four characteristics CBI teaching philosophy teaching mode.

\section{Teaching content used in business English teaching theoretical basis}

With economic globalization and China's increasing foreign exchange, social and workplace English language proficiency for higher requirements. To enable students to master the basic knowledge and basic skills in English, while the culture of their daily life and the workplace application ability, cultural awareness training for future career development and lifelong learning continue to lay the foundation [3]. According to my understanding, teaching business English teachers mostly use the traditional bottom-up teaching methods, from Business English syllabus and objectives, the teaching effect is not ideal. Teaching traditional bottom-up approach is to focus on grammar and language usage, showing linguistic knowledge to students through linear and organized manner, and to consolidate the knowledge gained through repeated practice out of context, ignoring learners environmental characteristics and language use. This teaching method is rarely able to stimulate students 'interest and motivation, and often increase students' anxiety. Therefore, under the new situation, how to better implement the secondary vocational school English syllabus, the effective realization of the goal of teaching syllabus requirement is an important issue related to the quality of training of personnel, should be subject to business English teaching profession and the research community attention.

Strengthen the practical application of Chinese martial arts. The present situation of Chinese martial arts teaching, strengthen the practical application of Chinese martial arts is a necessary means for the development of Chinese martial arts teaching. therefore, from the place of students interested in, in the Chinese martial arts class teaching more practical skills, fully arouse the enthusiasm of the students say, again in the process of practical teaching in Chinese martial arts education, cultivate students advocate quality of Chinese martial arts, develop a new generation of civil-military all-around students, with a strong will, let them to better fit into society. Let the students can not only learn skills but also learn the spirit of the Chinese martial arts culture [2]. They work in the future, inheriting the traditional culture and the spirit of the Chinese nation.

Improving Chinese martial arts teaching material. The content of the Chinese martial arts teaching should adapt to the development of society and the development of the student body and mind, optimization and improvement of Chinese martial arts teaching materials and teaching contents, changing course content "difficult, complex, partial, old" and obsessed with the present situation of book, is to make the students' interest in the new set of kung [3]. Optimization method is optimal set of Chinese martial arts skills combined with traditional culture method, the optimal set of methods of confrontational sports, reduced routine method of action, increase equipment routine with applicability and performing Chinese martial arts. Change the original boring, form a single teaching 
content, to ensure that the Chinese martial arts teaching content optimization on the implementation of scientific, guarantee the inheritance of Chinese traditional culture.

Increased investment in space equipment and construction. Chinese martial arts teaching can be carried out in the school; to solve the problem of space equipment is the necessary way [4]. Chinese martial arts Chinese martial arts venues and equipment are in class, the basis of the investment location equipment, Chinese martial arts teaching task is to complete the necessary condition of a good training and complete Chinese martial arts equipment can better stimulate students' interest in Chinese martial arts, to improve students' learning initiative.

\section{Content Teaching Business English Teaching}

Although the contents of teaching are collectively referred to as a "language and content integration," the teaching methods, but the "content" and "language" to produce a number of different understanding of CBI's operating mode. CBI traditional model has a "content" based immersion in the language-based themes and weights between curriculum and auxiliary mode between content and language. But no matter which model adopted, not only split the language and content of the relationship, in order to really achieve the effect of CBI's teaching. Short proposed language - content - tasks (hereinafter referred to as the "LCT") new teaching mode, teaching them how to solve the look and weigh the "language learning" and "professional learning content" relationship issues, thereby provide a reliable way for business English teaching.

Content-based teaching. "Content" refers to the business knowledge. In the CBI teaching, teachers with different business theme center, rather than in the form of language, functions and skills center to organize courses. Through the study of a particular subject matter acquire language communication skills [4]. As Dupuy said, CBI is a professor in the target language knowledge of a subject, thereby ensuring that students can acquisition target language, but also control of both the teaching of subject knowledge.

In Leaver \& Stryker summarized the CBI must have four basic characteristics, in addition to the first "Content-core" is the basis for the implementation of the framework of CBI teaching other three are teaching content requirements. Where the second is to use real corpus: core material (text, audio and video products, etc.) should be mainly from the development and use of native speakers of the corpus; the third is learning new information: learners should be aware of the new information in the target language and have ability based on the knowledge of the family culture and gradually learned the target language culture to evaluate new information; Fourth choose to meet the special needs of learners Materials: topic, subject content knowledge, teaching materials and learning activities should be identified and learners known to adapt to the needs and emotional needs, and should adapt the language level classes.

CBI's classrooms can be used on a particular business topic authentic material requires students not only to master the language of business, but also to understand business information, business information and summarize, interpret and evaluate.

Task-based teaching. Teaching content and teaching activities will be considered as the task of teaching, but the content of teaching in the "mission" is different from the simple to improve students' ability to use language is the language of communication tasks purposes [5]. In the classroom, "task" is not only involved in business language skills training, but also to help students understand the business field or use "procedural knowledge", this knowledge is mainly used to answer "how to do" or "how to" problems.

CBI teaching task is a "carriage." Students from the outset faced with a series of tasks. These tasks step by step guide students to complete collect, summarize, interpret and evaluate process information. These tasks are set in order to facilitate the input of that challenging business language, and teach a variety of learning strategies [5]. When students became familiar with these effective learning strategies and skills, and then encourage them to reduce the "cradle" of self-directed exploration of the subject. CBI teaching philosophy used in business English teaching purpose is to cultivate students' ability to independently learn business English. The ultimate aim is to enable students to language teachers to leave the nest, independent fly. 


\section{Implementation language teaching, teaching content, teaching methods integration tasks}

LCT mode cross section as the "glue" the same language, content and tasks of the three closely linked. Intersection of language and content, highlighting the significance of the business domain language teaching, business English language has its own unique place, they differ in vocabulary, language structure and textual forms [6]. Difficult for students learned these differences in foreign language, they can go to experience in the business of learning English, to imitate, to learn. Use English to communicate in the business process to consciously abide by the rules of the appropriate language to use.

Intersection of content and tasks, focus on the habit of thinking of business people. Refers to the habit of thinking is to explore problems or complete tasks. If you can not use effectively the habit of thinking for specific tasks, even if there thinking strategies and skills, do not have any value. For example, businessmen from different cultural backgrounds are very different in the habit of thinking, if not understand these differences will lead to the parties are unable to communicate [6]. Therefore, guide students to specific business tasks using appropriate habits of mind that will help improve students' ability to solve business problems.

Intersection of language and task reminders teacher attention to layout tasks explained. For learners, teachers in addition to verbal commands, but also issued written instructions for their reference, and most importantly, the teachers were asked to complete the task demonstration. In addition, teachers must ensure that students have the language skills needed to complete the task.

Task-based teaching. This study was based on the content of relying teaching theory, combined with business English curriculum requirements, teaching object characteristics and teaching conditions, relying on the contents of the design business English teaching model, and applied research in teaching practice [7]. As can be seen from the results of this study, this study design business English teaching model can rely on the contents of a certain extent, to effectively improve business English teaching effectiveness. Relying on English Teaching content type is effective in business English teaching practice, to a certain extent, enhance the learners' interest in learning English and initiative to improve vocational English teaching.

The value of this research, limitations and future research prospects. The results of the study demonstrated for the business of teaching students English teaching model relying on the contents of the more capable of causing business English learners' interest in learning English, to more effectively improve business English learning achievement, develop their English proficiency. It should be noted, CBI teaching mode application in practice to be applied flexibly according to the characteristics of the object and the actual needs of teaching, teaching methods and teaching fully incorporated in the learning of English, the difficulty of the task learners arrangements should be moderate, while authenticity and significance of learning [8]. Therefore, English teachers at school English teaching reform thinking and implementation should be further recognized that teaching English through CBI positive. Meanwhile, English teachers should be encouraged to combine practical and concrete environment to promote student teaching mode CBI to reform the traditional emphasis on language knowledge and usage, neglect teaching model language use, in order to improve teaching effectiveness.

\section{Conclusion}

Training complex business professionals much-needed innovation and business English teaching. CBI This LCT based Instruction around specific tasks related to the content and business start teaching activities for students seeking the right answers and complete the task in the process, learn to think, so as to master the language of business, the purpose of the exchange of business information. This in a real or relative real language environment, through the use of commercial content and learning a foreign language teaching model is more conducive to both students use English in everyday communication, but also the ability to use English for business communication. But it is worth noting that the implementation of a multi-mode LCT teaching challenges, such as curriculum, teaching materials, teaching staff, teaching equipment. Teachers should fully take into account the 
above factors and flexible use in business English classroom teaching, in order to make this teaching mode CBI to maximize the effect.

\section{Acknowledgement}

Fund project: Field teaching reform project of Neijiang normal college in 2016--"The business English teaching reform under the perspective of the CBI teaching concept". (Item Number: JG201611-326).

\section{References}

[1] W.Zh. Zhu, Business English teaching mode theoretical context, Characteristics and actual effect analysis, Journal of Guangdong university of foreign studies, 2010, vol.10, pp.22-27.

[2]L.T. Wang, CBI teaching idea into business English teaching effectiveness research, Journal of Beijing second foreign languages institute, 2013, vol.3, pp.74-79.

[3] Y.J. Liu, CBI teaching ideas in the teaching of business Chinese application, Liaoning normal university, 2012, vol.5, pp.43-46.

[4] Q.N. Dai, CBI teaching idea and teaching model, Foreign language teaching, 2014, vol.4, pp.18-22.

[5] T.G. Liu, The CBI teaching business English teaching mode in the concept of construction, Journal of Hunan business school, 2012, vol.12, pp.11-14.

[6] Y.P. Cheng, The CBI teaching concept to the medical English teaching enlightenment, Journal of Chinese higher medical education, 2008, vol.12, pp.77-78.

[7] P.R. He, The application of the CBI teaching in college English teaching at home and abroad research, Journal of contemporary education BBS, 2013, vol.5, pp.15-18.

[8] L.J. Huang. Based on the content of the teaching of business English teaching models study, Journal of Hangzhou University of electronic science and technology, 2009, vol.1, pp.69-72. 